\title{
Imparting training to rural women of fertilizer bags products
}

Received: 08.02.2017; Revised: 16.04.2017; Accepted: 03.05.2017

See end of the paper for authors' affiliations BHARTI SHARMA

Department of Textile and Apparel Designing, I.C. College of Home Science, C.C.S. Haryana Agricultural University, HISAR (HARYANA) INDIA

Email : bhartisharma2019@gmail.com
-ABSTRACT : Fertilizer bags are package material used for carrying the fertilizer from the manufacturing point to place of use i.e. factory to field. These bags are not recollected and reused for that vary purpose or otherwise. The present study was conducted to investigate to impart technical knowhow of making diversified products of fertilizer bag material. 10 women respondents of Harita village were selected due to easy approachability. The knowledge related to reuse of fertilizer bags, sizes and method of making utility articles, for making of diversified products was imparted to these women by organizing a training of ten days. Use of fertilizer bag material for making shopping bag, wall pocket, foot mat, mobile phone cover, hand fan were taught to the trainees. Each trainee stitched one article using fertilizer bag for making shopping bag, wall pocket, stool mat, mobile phone cover and hand fan. So there was an immense impact of the trainings on the trainees.

KEY WORDS: Fertilizer, Bags, Diversified, Knowledge, Training, Diversified products

- HOW TO CITE THIS PAPER : Sharma, Bharti and Punia, Praveen (2017). Imparting training to rural women of fertilizer bags products. Asian J. Home Sci., 12 (1) : 167-169, DOI: 10.15740/HAS/AJHS/12.1/ 167-169. 